\title{
Distributed generation and security of supply: Assessing the investment deferral
}

DOI:

10.1109/PTC.2009.5282277

Link to publication record in Manchester Research Explorer

\section{Citation for published version (APA):}

Wang, D. T. C., Ochoa, L. F., \& Harrison, G. P. (2009). Distributed generation and security of supply: Assessing the investment deferral. In 2009 IEEE Bucharest PowerTech: Innovative Ideas Toward the Electrical Grid of the Future/IEEE Bucharest PowerTech: Innovative Ideas Toward Electr. Grid Future https://doi.org/10.1109/PTC.2009.5282277

Published in:

2009 IEEE Bucharest PowerTech: Innovative Ideas Toward the Electrical Grid of the Future|IEEE Bucharest PowerTech: Innovative Ideas Toward Electr. Grid Future

\section{Citing this paper}

Please note that where the full-text provided on Manchester Research Explorer is the Author Accepted Manuscript or Proof version this may differ from the final Published version. If citing, it is advised that you check and use the publisher's definitive version.

\section{General rights}

Copyright and moral rights for the publications made accessible in the Research Explorer are retained by the authors and/or other copyright owners and it is a condition of accessing publications that users recognise and abide by the legal requirements associated with these rights.

\section{Takedown policy}

If you believe that this document breaches copyright please refer to the University of Manchester's Takedown Procedures [http://man.ac.uk/04Y6Bo] or contact uml.scholarlycommunications@manchester.ac.uk providing relevant details, so we can investigate your claim.

\section{OPEN ACCESS}




\title{
Distributed Generation and Security of Supply: Assessing the Investment Deferral
}

\author{
David T-C. Wang, Luis F. Ochoa, Member, IEEE, and Gareth P. Harrison, Member, IEEE
}

\begin{abstract}
Technology advances together with environmental concerns have paved the way for the increasing integration of Distributed Generation (DG) seen over recent decades, having an important role in governments' targets. While several technical challenges are now faced by Distribution Network Operators (DNOs) in order to properly accommodate DG developments, one of the major and well-recognised benefits is the ability of DG to defer future demand-related investments. Here, a more integral approach is presented where also reinforcements required by system security standards (e.g., N-1) are taken into account. This methodology builds on a previous work where the successive elimination method and multistage planning were utilised to quantify the investment deferral brought about by DG. The DG contributions to system security provided by the UK Engineering Recommendation P2/6 are adopted, enabling the methodology to quantify the deferment produced by DG considering both demand growth- and system security-related investments. The method is applied to a UK generic distribution network. Results show that significant economic benefits can be harnessed when strategically incorporating DG at the planning stage.
\end{abstract}

Index Terms-- Distribution networks, distributed generation, investment deferral, planning

\section{INTRODUCTION}

D IVERSIFICATION of the energy mix is one of the main challenges in the energy agenda of governments worldwide. However, technology advances together with environmental concerns have paved the way for the increasing integration of Distributed Generation (DG) seen over recent decades, having an important role in governments' targets. Indeed, combined heat and power (CHP) and renewable technologies are being encouraged in EU Member States, and are expected to have an increasing penetration in the European distribution networks. This scenario presents Distribution Network Operators (DNOs) with several technical challenges in order to properly accommodate DG developments $[1,2]$. However, depending on various factors, such as location, size, technology and robustness of the network, DG might also be beneficial to DNOs [3-6].

Since DG can be accommodated in distribution networks

This work is part-funded through the EPSRC Supergen V, UK Energy Infrastructure (AMPerES) grant in collaboration with UK electricity network operators working under Ofgem's Innovation Funding Incentive scheme - full details on http://www.supergen-amperes.org/.

The authors are with the Institute for Energy Systems, School of Engineering, The University of Edinburgh, Edinburgh, EH9 3JL, U.K. (e-mail: d.wang@ed.ac.uk, luis_ochoa@ieee.org, gareth.harrison@ed.ac.uk). relatively close to the load, it has the potential to alleviate network power flows. While power loss reduction is a direct technical benefit for the DNO, its economic impact will depend on the regulatory framework for improving the efficiency of DNOs. Therefore, a tangible economic benefit for DNOs is the decongestion of network assets, DG has the ability to help avoid or defer reinforcements required by demand growth in a given horizon [7-11].

The quantification of the benefits (and negative impacts) brought about by DG need to be quantified in order to create a level playing field. In the UK, the Renewables Obligation scheme promotes DG by mandating energy suppliers to source a given proportion of their electricity from green technologies. On the other hand, considering the important role of DNOs in facilitating the connection of DG, Ofgem, the electricity regulator, has also introduced incentives where DNOs are paid capital and operational expenditures due to the integration of DG. However, from the distribution planning perspective, where demand-led reinforcements traditionally represent costly CAPEX, the effect that DG might have on deferring such investments has not been considered.

At a European level, the Article 14/7 of the Directive 2003/54/EC [12] states: "When planning the development of the distribution network, energy efficiency/demand-side management measures and/or distributed generation that might supplant the need to upgrade or replace electricity capacity shall be considered by the distribution system operator". Nonetheless, there is no specification on how to implement it.

Brown et al. [13] proposed a successive elimination algorithm for distribution network expansion considering the specific siting of generation units. It presents a simple planning technique makes it possible to calculate the investments required by the non-DG and DG scenarios, thus obtaining the corresponding monetary benefit. Mendez et al. [8] demonstrated the impact of different DG penetration and concentration levels and technology mixes on allowable load growth without the need for reinforcements. Gil and Joos [9] developed an approach based on the amount of network currents reduced by a DG unit, assuming that the reinforcement deferment was equivalent to the time required for the currents to reach the pre-DG level.

The methodology proposed in this paper builds on a previous work [10] where the successive elimination (SE) method from [13] was combined with a multistage planning in order to defer demand-led investments. Given that reinforcements are not only related to network capacity but 
also to security of supply standards, such as the UK Engineering Recommendation (ER) P2/6 [14], this work extends the initial proposal to cater for those requirements. Particularly, ER P2/6 allows DG, to some extent, to contribute to the system security by acknowledging a fraction of the nominal capacity of the generator during a first circuit outage (FCO). Incorporating this contribution enables the methodology to quantify the impacts of DG on security-related investments.

In this work, a UK generic distribution network [15] is evaluated considering the connection of non-intermittent DG units (e.g. CHP, CCGT). The investment deferral will be considered as the one that occurs when reinforcements that are required to prevent system constraint violations, such as thermal limits and network security, are postponed as a result of DG connection. Single DG connections are examined in order to investigate the corresponding effects on investment deferral.

This paper is structured as follows: the contribution of DG to system security adopted by UK ER P2/6 is explained in Section II. In Section III, the proposed methodology to assess the investment deferral is presented. The generic UK distribution network is evaluated and results discussed in Section IV. Finally, conclusions are drawn in Section V.

\section{CONTRIBution OF DG TO SyStem Security (ER P2/6)}

Generation connected to the distribution network might be able - to some extent - to contribute to system security, i.e., to maintain part of the supply to a defined level of demand under defined outage conditions. Engineering Recommendation P2/6 [14] superseded ER P2/5 (1978) by updating previous contribution factors to account for modern types of DG. These (indicative) contribution factors, known as $F$ factors (as a percentage of the declared gross capability of a DG plant), were produced as a function of DG technology and number of units. Table I presents the ER P2/6 $F$ factors for different types of non-intermittent generation.

TABLE I

\begin{tabular}{c|cccccccccc}
\multicolumn{10}{c}{ F FACTORS IN \% FOR NON-INTERMITTENT DG [14] } \\
& \multicolumn{10}{c}{ Number of units } \\
\hline Type of generation & 1 & 2 & 3 & 4 & 5 & 6 & 7 & 8 & 9 & $10+$ \\
\hline Landfill gas & 63 & 69 & 73 & 75 & 77 & 78 & 79 & 79 & 80 & 80 \\
CCGT & 63 & 69 & 73 & 75 & 77 & 78 & 79 & 79 & 80 & 80 \\
CHP sewage treatment using & 40 & 48 & 51 & 52 & 53 & 54 & 55 & 55 & 56 & 56 \\
a spark ignition engine & & & & & & & & & & \\
CHP sewage treatment using & 53 & 61 & 65 & 67 & 69 & 70 & 71 & 71 & 72 & 73 \\
a Gas Turbine & 53 & 61 & 65 & 67 & 69 & 70 & 71 & 71 & 72 & 73 \\
Other CHP & 58 & 64 & 69 & 71 & 73 & 74 & 75 & 75 & 76 & 77 \\
Waste to energy & & & & & & & & &
\end{tabular}

To illustrate the impact of the $F$ factors on planning investments, consider Fig. 1 where an example system with a DG plant is presented. In Fig. 1, two identical non-intermittent (CCGT) generation units composed the DG plant, each with declared net capacity of 20MW. The DG plant is connected to a bus with a 60MW load. Power supply is provided by two
45MVA, 0.95 power factor transformers with 1.3 cyclic rating factor.

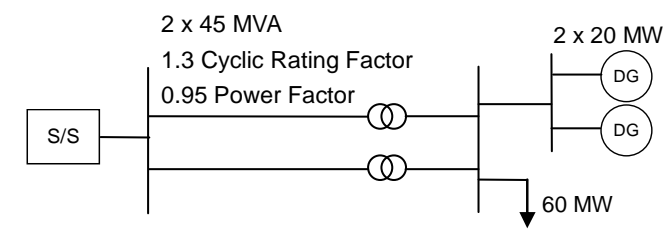

Fig. 1 Example system with DG.

Since the load is $60 \mathrm{MW}$, only the first circuit outage, i.e., one of the transformers, needs to be considered [14].. Without DG, the maximum amount of load that can be supplied following the outage of the most crucial circuit, i.e. the Network Capability (NC), would be:

$$
N C \text { after } F C O=1 \times 45 \times 1.3 \times 0.95=55.6 \mathrm{MW}
$$

Clearly, the demand cannot be met. If, however, DG is to be taken into account, the $F$ factor for this particular plant with two generation units is 69\% (Table I). Therefore, the DG plant connected to the load bus would have an effective contribution to system security equal to:

$$
D G \text { Contribution }=0.69 \times 2 \times 20=27.6 \mathrm{MW}
$$

This contribution to the NC allows up to $83.2 \mathrm{MW}$ of demand to met after the FCO enabling the the circuit to fulfill the security of supply requirements without further investment.

\section{MethodOLOGY}

Distribution investment deferral has been investigated from different angles. In [8], the deferment was considered as the load growth that certain penetrations and concentration levels of different DG technologies would allow the network to achieve without requiring further capacity upgrades. However, while the results clearly show the impact DG has on postponing investments, this particular study cannot be used for quantifying the relative benefit that a generation unit may bring about according to its location.

Placing and sizing of DG units are not necessarily decided by DNOs. In fact, it is mainly availability of resources that determines a specific connection site. Nonetheless, studies that supply information regarding the most beneficial connections points and generation capacities - from the network point of view - might be used to create a framework for incentives or charging schemes. In this context, in [9], the ability of a single DG unit to defer investments was calculated for every node of a given distribution network. This approach provides the relative deferment in monetary units per connected $\mathrm{kW}$ or MW of DG. The adopted deferral time in [9], however, was not appropriate since it considered the time required for the network power flows to return to the level prior to the connection of DG. The economic benefits of DG can only be quantified accurately if the deferment is relative to the time when the reinforcement costs are incurred [10].

Non-intermittent generation is able to offset local demand, and therefore postpone load growth-led investments [10]. Nevertheless, system security-driven reinforcements (e.g., 
redundancy of circuits) cannot rely entirely on DG plants due to reliability and risk issues. It is in this context, considering the contribution to system security provided by the UK ER $\mathrm{P} 2 / 6$, that a more integrated approach to assessing demand growth and system security requirements in driving network investment.

In order to evaluate the effect that the placement of generation units may have on the expansion planning costs, the reinforcements required by the original (non-DG) and DG scenarios need to be determined. For this purpose, a two-phase approach is adopted for a given case of load growth, planning horizon, and presence or absence of new DG. Firstly, the successive elimination method is used to evaluate the capacity upgrades needed by the distribution network. Secondly, the multistage planning analysis provides the necessary schedule for the investments. Finally, the total expansion planning costs are calculated for the studied case. The difference between the costs required for the original scenario and the DG scenarios will correspond to the value of investment deferral produced by the connection of new generation. The following subsections describe in detail each phase of the method.

\section{A. Successive Elimination Method}

The successive elimination (SE) method presented in [13] is adopted to determine the most cost-effective network expansion combinations at the end of the planning horizon. While metaheuristic optimization planning strategies for distribution networks commonly found in the literature (e.g., Genetic Algorithms, Simulated Annealing, Tabu Search) may give a better solution than so-called greedy heuristics like SE, the latter will still produce a satisfactory solution. The method is straightforward, making the process easily understandable by the planner due to the use of a cost-effectiveness index.

The fundamental concept of the SE method is to initially overbuild the network with all reinforcement candidates including transformers and lines. Then, the least cost-effective option is removed until the further removal of any remaining candidate would cause system constraint violations during the planning horizon. Fig. 2 shows the flow chart for the SE technique. The steps of the methodology are as follows:

Step 1. Consider the load corresponding to the year at the end of the planning horizon.

$\underline{\text { Step 2 }}$. Identify all the required network expansion options and connect them to the network. Verify that the overbuilt network has no constraint violations, i.e., thermal and voltage limits due to both the demand and system security requirements (FCO or N-1 criteria)..

Step 3. Change the status of each expansion candidate in turn and verify there are no constraints violated (again, for both demand and system security). In this method, the status change, is called an option, and can either be the deletion or type change of the equipment. If so, calculate the cost-effectiveness due to the change using the following equation:

$$
C E_{a}=\frac{P-P_{a}}{\text { Cost }_{a}}
$$

where $C E_{a}$ is the cost-effectiveness measurement of option $a$ in
MW/\$, $P$ is the total MW flow of the network, $P_{a}$ is the total MW flow of the network without option $a$, and Cost $_{a}$ is the cost of option $a$. The candidate is then put into an elimination list. Repeat Step 3 until all expansion candidates have been examined.

Step 4. Compare the cost-effectiveness of all the options in the elimination list. Find out the least cost-effective option and delete it. If the list is not empty, go to Step 3, otherwise go to Step 5.

Step 5. The final expansion plan has been determined. Save the remaining candidates for the multistage planning analysis.

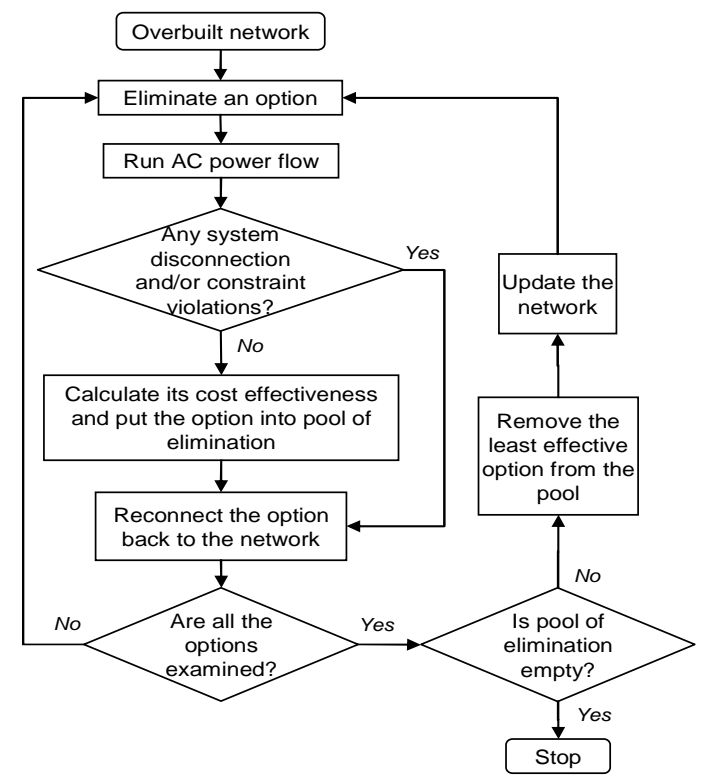

Fig. 2 Flow chart of the successive elimination method.

\section{B. Multistage Planning Analysis}

The purpose of the multistage planning analysis is to schedule the implementation of the reinforcements obtained from the SE method along the planning horizon. Thus, by scheduling the reinforcements according to the demand growth it is possible to evaluate the investment deferral produced by the connection of DG at different stages. Fig. 3 shows the flow chart for the multistage planning. The steps of the procedure are as follows:

Step 1. Load network configuration at the end of planning horizon, which is determined by the SE method.

Step 2. Connect DG.

Step 3.Identify the candidates which are not required this year. Eliminate one with the lease cost-effective index. Repeat the step until all the remaining options are essential to prevent any system violations (demand and system security) this year.

Step 4. Stop if it is the base year. Otherwise update the network with forecasted load at the year before the current one, then go to step 3 . 


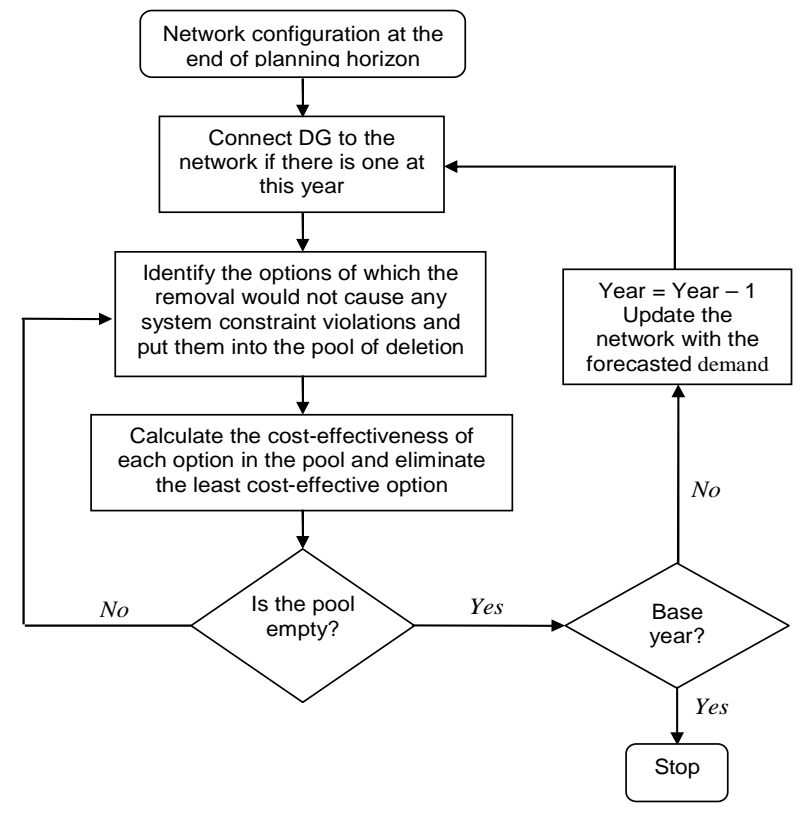

Fig. 3 Flow chart of the multistage planning.

\section{Investment Deferral}

From the previous two subsections, the capacity upgrades for the network expansion and the corresponding scheduling of investments can be determined. To obtain the total investment incurred by each planning scenario studied, the present value of each upgraded asset should be calculated. In this way, the total present value (PV) cost of the plan is given by:

$$
P V=\sum_{t=1}^{h} \sum_{i=1}^{n} \frac{C_{i, t}}{(1+\rho)^{t}}
$$

where $h$ is the number of years in the planning horizon, $n$ is the number of reinforcements required for year $t, C_{i}$ is the cost of asset $i$ required for year $t$, and $\rho$ is the annual interest rate.

The investment deferral, as a benefit brought about by the connection of new DG, is then calculated by subtracting the $\mathrm{PV}$ of the total investment required by a given DG planning scenario from that of the original (no new generation) planning scenario:

$$
\text { Inv. Deferral }=\left.\sum_{t=1}^{h} \sum_{i=1}^{n} \frac{C_{i, t}}{(1+\rho)^{t}}\right|_{n o D G}-\left.\sum_{t=1}^{h} \sum_{i=1}^{n} \frac{C_{i, t}}{(1+\rho)^{t}}\right|_{D G}
$$

\section{APPLICATIONS}

\section{A. Network and Assumptions}

The methodology proposed is applied to the 81-bus meshed suburban distribution network depicted in Fig. 4. The full specification of EHV Network 4 can be obtained in [15].
Power is supplied to the meshed network from a single grid supply point and two interconnectors linking neighbouring networks at $132 \mathrm{kV}$. There are 32 loads scattered throughout the network of different voltage levels (33 and $11 \mathrm{kV})$. The total peak load at the base year is $151 \mathrm{MW}$. For the system security requirements, it is considered the outage of single elements of the network, i.e., N-1 constrained. The outage is applied to each line and transformer, apart from those equipments connected between the interconnectors and the main network, and those single transformers connected to loads less than 12MW (according to ER P2/6 are not required to be restored immediately). It is assumed an annual load growth of $2 \%$ and the planning horizon is set to 10 years. Any reinforcement, which is postponed beyond the horizon, is assumed to be connected at year 10 instead of complete avoidance of the reinforcement. The annual interest rate is $6 \%$.

\section{B. Analysis without $D G$}

The reinforcements required in the case without DG, along with their connection schedules and costs, are shown in Table II. The term 'upgrade' refers to the replacement of existing lines, whereas 'parallel' indicates that the reinforcements are connected in parallel with the existing ones.

The total planning cost in present value is US $\$ 2.9 \mathrm{~m}$. Most of the reinforcements will be required within the first two years. T112-1112 is the only transformer required. This is due to the fact that the load at bus 1112 is greater than $12 \mathrm{MW}$, needing to meet the system security requirement stated in ER P2/6.

\section{TABLE II}

REINFORCEMENTS REQUIRED AND THEIR COST IN PRESENT VALUE WITHIHN THE PLANNING HORIZON

\begin{tabular}{ccccccc} 
Name & Type & Capacity (MVA) & Cost $($ US\$k/km) & Length $(\mathrm{km})$ & Year & P.V. cost (US\$k) \\
\hline L101-103 & upgrade & $2 \times 120$ & 400 & 4.2 & 7 & 1117.30 \\
L103-105 & parallel & $1 \times 120$ & 200 & 3.5 & 8 & 439.19 \\
L301-304 & parallel & $1 \times 30$ & 120 & 1.1 & 1 & 124.53 \\
L304-326 & parallel & $1 \times 30$ & 120 & 0.9 & 2 & 96.12 \\
L311-337 & parallel & $1 \times 30$ & 120 & 0.5 & 0 & 60.00 \\
L313-318 & parallel & $1 \times 30$ & 120 & 0.5 & 2 & 53.40 \\
L313-319 & parallel & $1 \times 30$ & 120 & 1.6 & 0 & 192.00 \\
L319-342 & parallel & $1 \times 30$ & 120 & 0.2 & 8 & 15.06 \\
L341-342 & parallel & $1 \times 30$ & 120 & 1.7 & 0 & 204.00 \\
L111-112 & parallel & $1 \times 120$ & 200 & 0.6 & 0 & 120.00 \\
T112-1112 & parallel & $1 \times 30$ & 500 & - & 0 & 500.00 \\
\hline
\end{tabular}

\section{Impact of DG Locations and Capacity}

A single generation unit with declared gross capability of $10 \mathrm{MW}$ will be connected at different buses of the EHV Network 4 in order to assess the locational effects of DG on the investment deferral. A contribution to system security, i.e., $F$ factor, equal to $80 \%$ is assumed. In other word, during the $\mathrm{N}-1$ analyses, the DG plant is contributing to the network capability with $8 \mathrm{MW}$. Fig. 5 presents the obtained values. 


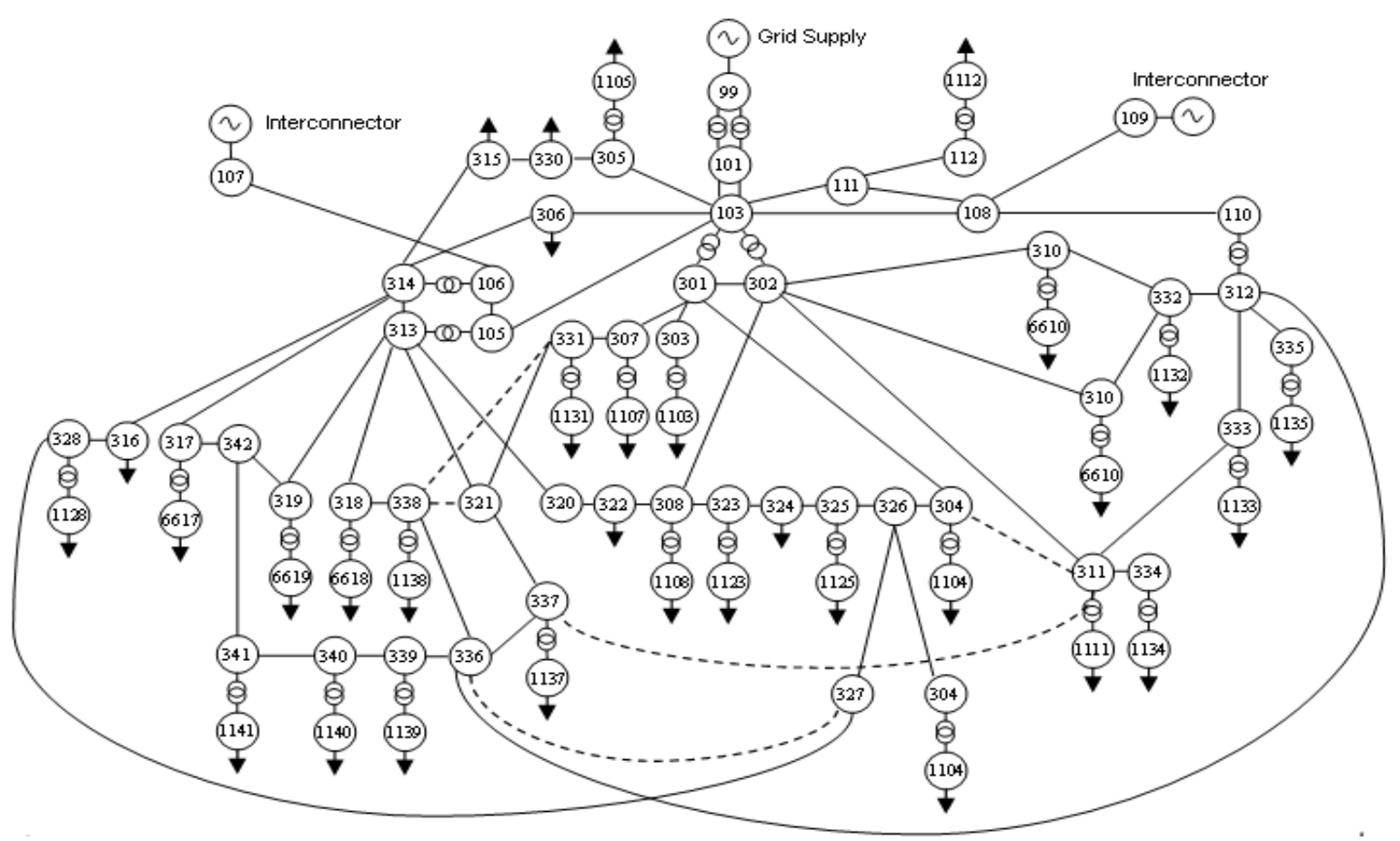

Fig. 4 UK GDS EHV Network 4 - Meshed suburban network.

Each bar can be further classified into two categories: the benefits obtained from deferring the $132 \mathrm{kV}$ and $33 \mathrm{kV}$ reinforcements. In ER P2/6, the contribution by a DG plant is only credited by its ability to affect the adjacent equipments where the generation is connected to. However, as these results indicate, DG has clear impact on deferring system security-led reinforcements at higher voltage levels, where the investments are much more expensive.

As expected, the deferment of investments is highly sensitive to the generation site. The 10M DG plant connected

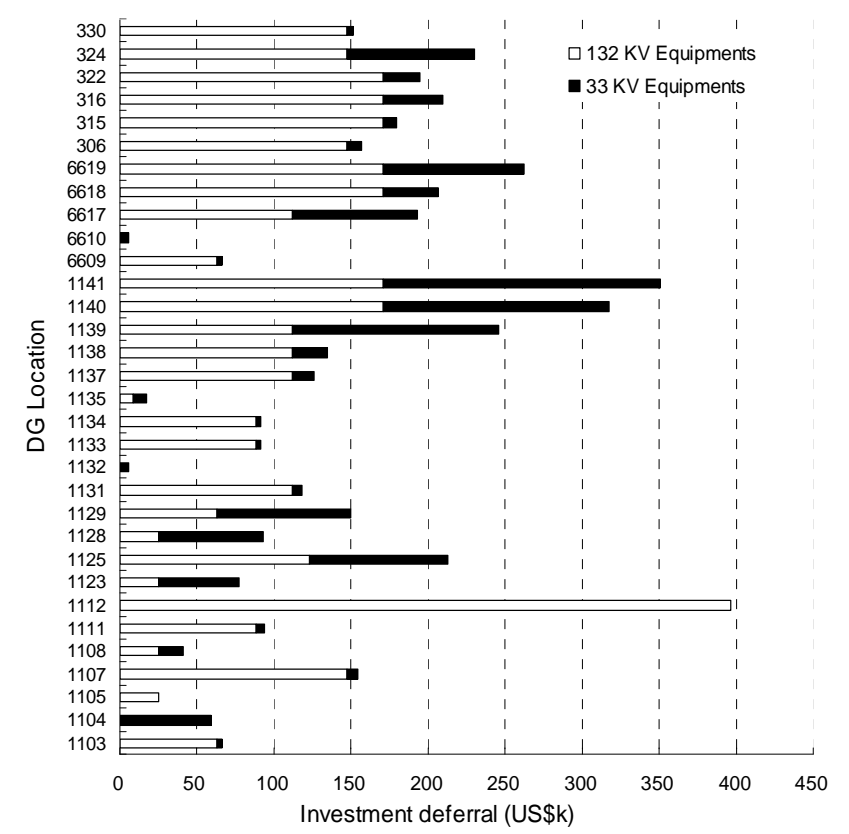

Fig. 5 Investment deferral benefits according to different DG locations. at bus 1112 yields US\$397k of savings, while this figure is only US\$5.87k when DG is located at bus 6610 .

The effectiveness of DG at different locations to defer the scheduled reinforcements (non-DG case, Table II) is depicted in Fig. 6. It is clear that the benefits obtained by DG at bus 1112 are mainly from its ability to postpone the investment of the transformer connecting bus 112 and 1112 from base year to year $10(5 a)$.

The patterns of years of deferments of adjacent lines 301304 and 304-306 are, in general, in phase across different DG

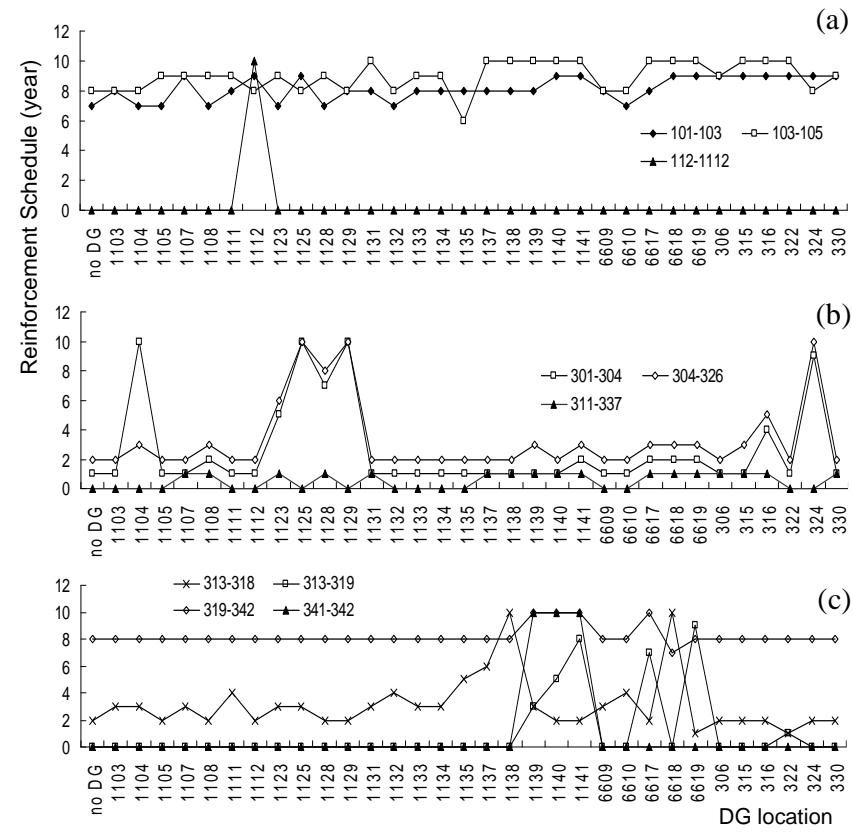

Fig. 6 Impact of DG at different locations on the schedule of reinforcements at (a) $132 \mathrm{kV}$, (b) central part, and (c) left part of the network. 
locations (Fig. 6b). This occurs since both lines are required to prevent system violations under the same contingent event, i.e. disconnection of line 308-323 would cause the overloads of both lines. DG at bus 324, 1125 and 1129 are among the most effective locations, at which the connection of the two lines are postponed to year 10. The connection of DG at bus 1128 , which is located at the end of line 327-328, is also effective by injecting extra power to support the loads at the central part of the network via the path between bus 326 and 328 during the contingency (loss of line 308-323). Under N-1 security condition, DG at adjacent locations may result in very different impact on the schedule of same reinforcement as well as the total benefits quantified. Although bus 1108 is relatively close to bus 324, DG at this location can not have any contribution to defer the investments of lines 301-304 and 304-326 during the loss of line 308-323.

According to Fig. 5, DG at bus 1139,1140 and 1141 yield greatest benefits from deferring the $33 \mathrm{kV}$ reinforcements. The reasons are justified in Fig. 6c. The schedule of connecting line 341-342 is highly sensitive to DG locations; it can be postponed to the end of planning horizon only when DG is connected at these three locations.

Not all DG imposes positive impact on the network. An example is when DG is connected at bus 1135. The DG defers the schedule of line 313-318 to year 6 but also brings the time of new line 103-105 connection two years closer to the present than the case without DG. Fig. 7 shows the reinforcement schedule affected by the increasing DG output at bus 1135 .
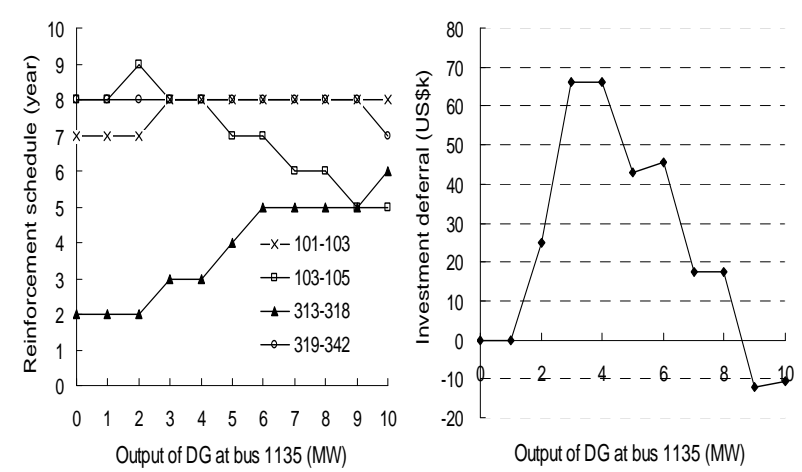

Fig. 7 Impact of DG output at bus 1135 on reinforcement scheduling and investment deferral.

During the loss of 108-110, extra power flow flows through line 313-318 and line 312-336 to support the loads at the right part of the network (bus 1111, 1134 etc). This contingency results in overloading the line 313-318. Therefore, the increase of DG output at bus 1135 would mitigate the power flows hence to defer the investment time of new line 313-318. However, under another contingency, when line 103-105 is tripped, power will flow from bus 312 to bus 326 to feed the loads at right part of the network. When DG output at bus 1135 is greater than the load $(4.5 \mathrm{MW})$ of the same bus, additional power will flow through the line 312-336 and to an extend, which starts causing the line to overload, as the consequence, new parallel line 103-105 has to be connected earlier to prevent the overloading during the contingency (loss of line 103-105).

According to Fig. 7, additional cost is imposed on new line 103-105 as the DG output increases beyond 4MW. The total benefits therefore reach its maximum at $4 \mathrm{MW}$ output and then start to drop. As the DG output increases to $9 \mathrm{MW}$ and above, it in fact imposes net economic losses to the network. The guidelines provided by ER P2/6 may be inappropriate here and it will not minimise the risks of the agreement made between DNO and DG developer: the advantages obtained by $8 \mathrm{MW}$ DG at bus 1135 are higher than 10MW which could overestimate the benefits if DG output is actually greater than $8 \mathrm{MW}$ at the time when the maximum load occurs. One possible solution for this case could be to make an agreement in which the real DG output at this time is limited under 8MW therefore preventing the negative impact on the network.

Fig. 8 summarizes the sensitivity of investment deferral per MW connected to different DG locations. Clearly, not only the location plays a major role, but also it cannot be assumed that increasing DG output at a given site will always defer investments. Apart from DG at bus 1104, 1132 and 6610, where DG has negligible impact on all the reinforcements, DG connected at other locations presents a significant difference between the average and maximum sensitivity. The maximum

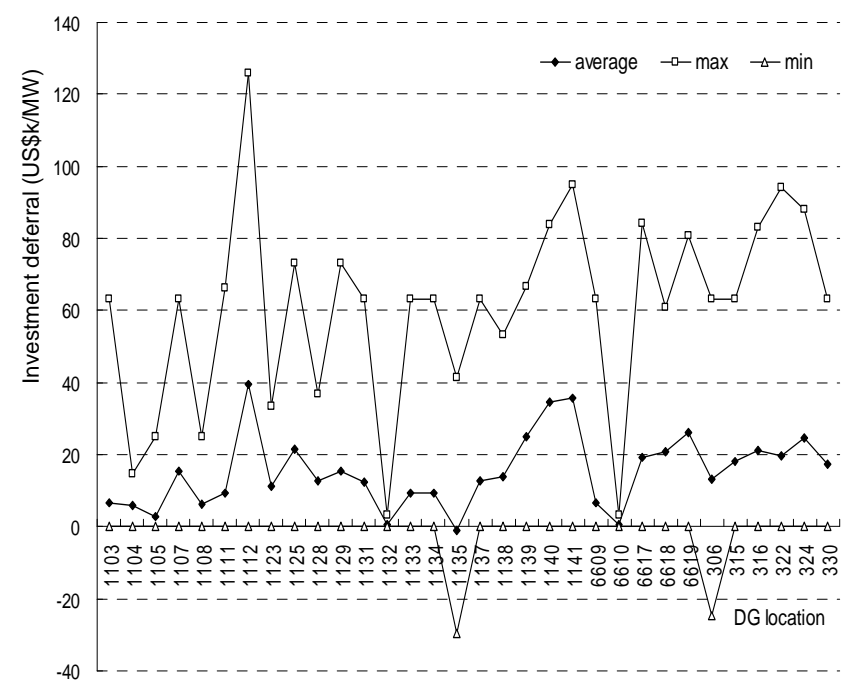

Fig. 8 Range of investment deferral obtained per MW increases of DG at different locations.

sensitivity of benefits occurs when next additional MW of DG would involve the investment deferral of the equipments connected at $132 \mathrm{kV}$ level of network. However, since the effectiveness of postponing the connection of new $132 \mathrm{kV}$ equipments is less than the impact DG has on the $33 \mathrm{kV}$ equipments, the average benefit sensitivity is brought down as most of time the additional MW of DG only affect either none or $33 \mathrm{kV}$ reinforcements which are less expansive.

\section{Strategy to Maximise Investment Deferral}

It is valuable for DNOs to understand how to deploy DG, in terms of location and size, to maximise the investment 
deferral. Here, a simple sensitivity analysis is used to find the minimum DG penetration required to achieve so. Starting from the location where the connection would affect the most expensive reinforcements, and then the output of DG is increased until there are no further additional benefits gained. The same process is repeated for DG at next selected location. The result of the deployment of DG is shown in Table III.

TABLE III

DG DEPLOYMENT TO MAXIMIZE TOTAL BENEFITS

\begin{tabular}{c|c|c|c} 
DG Location & Output (MW) & F Factor \% & Net declared capacity (MW) \\
\hline 1111 & 5 & 80 & 6.25 \\
1125 & 7 & 80 & 8.75 \\
1141 & 8 & 80 & 10 \\
6618 & 5 & 80 & 6.25 \\
6619 & 5 & 80 & 6.25 \\
\hline Total & 30 & --- & 37.5
\end{tabular}

In total $30 \mathrm{MW}$ of $\mathrm{DG}$ is required to defer all the reinforcements to year 10 . The total deferment is US\$811k, which is equivalent to approximately $28 \%$ of the planning costs without considering DG. The saving would considerably be more if some of the reinforcements are in fact avoided.

The credits given to a DG plant may not merely depend on its location and size but also the existence of other DG developments. The existence of line 311-337 has multiple functions. Firstly, it prevents the overloads of line 301-311 during the outage of line 312-333. Secondly, it also avoids line $312-336$ to overload when line 103-105 is tripped, before another parallel line 103-105 is connected. Therefore, although DG at bus 1111, 1133 and 1134 can effectively solve the first contingent scenario (disconnection of line 312-333), the credits can not be given until the second contingency (disconnection of line 103-105) no longer requires line 311337 to avoid any overloading. From Table III, DG connect at bus 1141(8MW), 6618(5MW) and 6619(5MW) together are capable of solving the second contingency and relieve the amount of power flowing through line 312-336 to support the loads at left part of the network, hence prevent the overloading of line 312-336 even without the connection of line 311-337. As shown in Fig. 5, DG can not have beneficial impact on deferring the investment in line 311-337 itself regardless the location. It is the combination of DG at the selected locations that could defer the connection of line 311-337 from year 0 to the end to planning horizon. Therefore, DG at bus 1111, 1141, 6618 and 6619 might share the benefits of the investment deferral of line 311-337, despite it is the DG at bus 1111 which in fact has the much more impacts on the line than the other three locations.

\section{CONCLUSIONS}

An approach for quantifying the impacts that DG may have on the deferment of demand- and system security-related network reinforcements was developed. A successive elimination technique along with a multistage planning analysis was adopted in order to determine the required investments (due to both demand growth and system security) and their corresponding scheduling. Knowledge of the required assets and their commissioning time along the planning horizon enables identification of those assets affected by the connection of DG, making it possible to obtain the corresponding new total investment cost.

Security of supply standards increase the need of reinforcements in distribution networks. Results demonstrated that significant benefits, in terms of investment deferral, can be harnessed if the DG contribution to system security ( $F$ factors, ER P2/6) is taken into account. This more integral approach for assessing the planning expansion problem is, however, no strange to the location effects of DG. Indeed, results clearly show that the deferment varies significantly with the location and size of the generator.

DNOs are usually not able to own generation in many countries, such as UK. However, with stricter efficiency targets set by regulators, it would be of great value for DNOs to integrate DG into the planning process.

\section{REFERENCES}

[1] P. P. Barker and R. W. De Mello, "Determining the impact of distributed generation on power systems: part 1 - radial distribution systems," presented at IEEE Power Engineering Society Summer Meeting, 2000.

[2] C. L. Masters, "Voltage rise - the big issue when connecting embedded generation to long $11 \mathrm{kV}$ overhead lines," IEE Power Engineering Journal, vol. 16, pp. 5-12, 2002.

[3] P. A. Daily and J. Morrison, "Understanding the potential benefits of distributed generation on power delivery systems," presented at Rural Electric Power Conference, 2001.

[4] P. Chiradeja and R. Ramakumar, "An approach to quantify the technical benefits of distributed generation," IEEE Trans. on Energy Conversion, vol. 19, pp. 764-773, 2004.

[5] D. M. Cao, D. Pudjianto, G. Strbac, A. Martikainen, S. Karkkainen, and J. Farin, "Costs and benefits of DG connections to grid system Studies on the UK and Finish systems," DG-GRID project - European Commission Dec. 2006.

[6] L. F. Ochoa, A. Padilha-Feltrin, and G. P. Harrison, "Evaluating distributed generation impacts with a multiobjective index," IEEE Trans. on Power Delivery, vol. 21, pp. 1452-1458, 2006.

[7] R. C. Dugan, T. E. McDermott, and G. J. Ball, "Planning for distributed generation," in IEEE Industry Applications Magazine, vol. 7, 2001, pp. 80-88.

[8] V. H. Mendez, J. Rivier, J. I. de la Fuente, T. Gomez, J. Arceluz, J. Marin, and A. Madurga, "Impact of distributed generation on distribution investment deferral," International Journal of Electrical Power \& Energy Systems, vol. 28, pp. 244-252, 2006.

[9] H. A. Gil and G. Joos, "On the quantification of the network capacity deferral value of distributed generation," IEEE Trans. on Power Systems, vol. 21, pp. 1592-1599, 2006.

[10] D. Wang, L. F. Ochoa, G. P. Harrison, C. J. Dent, and A. R. Wallace, "Evaluating investment deferral by incorporating distributed generation in distribution network planning," presented at 16th Power Systems Computation Conference (PSCC'08), Glasgow, 2008.

[11] G. P. Harrison, A. Piccolo, P. Siano, and A. R. Wallace, "Exploring the trade-offs between incentives for distributed generation developers and DNOs," IEEE Trans. on Power Systems, vol. 22, pp. 821-828, 2007.

[12] "Directive 2003/54/EC of the European Parliament and of the Council of 26 June 2003 concerning common rules for the internal market in electricity and repealing Directive 96/92/EC.," in European Commission, 2003.

[13] R. E. Brown, X. F. J. Pan, and K. Koutlev, "Siting distributed generation to defer T\&D expansion," presented at IEEE PES Transmission and Distribution Conference and Exposition, 2001.

[14] Energy Networks Association (ENA), "Engineering Recommendation P2/6 - Security of Supply," 2006.

[15] "United Kingdom Generic Distribution System (UK GDS)," vol. 2008: Distributed Generation and Sustainable Electrical Energy Centre. 


\section{BIOGRAPHIES}

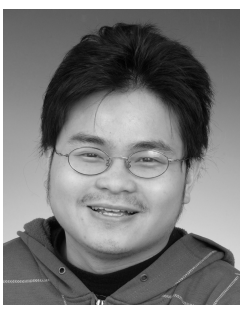

David T.-C. Wang received the BEng (Hons) from University of Auckland, New Zealand, in 2005, and the M.Sc. degree from the University of Edinburgh, U.K., in 2006.

$\mathrm{He}$ is currently pursuing a $\mathrm{PhD}$ at the same institution. His research interests include distribution network planning and analysis considering impacts of distributed generation.

$\mathrm{Mr}$ Wang is a member of the Institution of Engineering and Technology (IET).

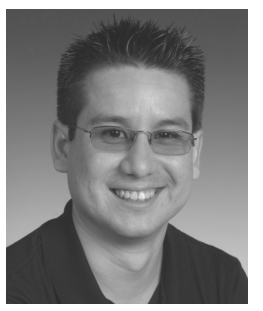

Luis F. Ochoa (S'01-M'07) is a Research Fellow at the Institute for Energy Systems, School of Engineering, University of Edinburgh, U.K. He obtained the Graduate degree from the National Engineering University (UNI), Lima, Peru, in 2000, and the M.Sc. and Ph.D. degrees from Sao Paulo State University (UNESP), Ilha Solteira, Brazil, in 2003 and 2006, respectively.

His current research interests include distribution system analysis and distributed generation. Dr. Ochoa is also member of the Institution of Engineering and Technology (IET).

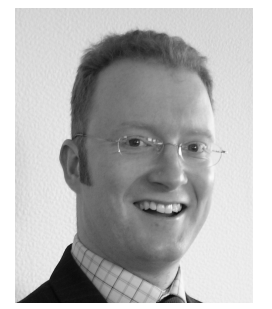

Gareth P. Harrison (M'02) is a Senior Lecturer in Energy Systems in the School of Engineering, the University of Edinburgh, Edinburgh, U.K.

His research includes network integration of distributed generation and analysis of the impact of climate change on the electricity industry.

Dr. Harrison is a Chartered Engineer and member of the IET. 